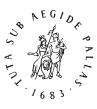

B R I L L

\title{
Teaching Kindness: The Promise of Humane Education
}

Arbour, R., ${ }^{a}$ Signal, T., ${ }^{b} \&$ Taylor, N. ${ }^{\mathrm{c}}$

a) Department of Behavioural \& Social Sciences, Central Queensland University E-mail: t.signal@cqu.edu.au

b) Department of Behavioural \& Social Sciences, Central Queensland University

c) School of Sociology, Flinders University

\begin{abstract}
Although the popularity of Humane Education Programs (HEP) as a method of teaching compassion and caring for all living beings is increasing, there is a need for rigorous, methodologically sound research evaluating the efficacy of HEP. Recent calls for the inclusion of HEP within broader humanistic, environmental, and social justice frameworks underline the importance of HEP beyond a simple "treatment of animals" model. Lack of methodological rigor in the majority of published HEP studies (e.g., absence of a control group) and dispersal across disparate fields (with differing indices of efficacy), however, means that there is a potential for the popular use of HEP to outstrip our understanding of the variables that impact efficacy. The current study discusses some of these issues and presents a pilot study of a literature-only HEP intervention. Comparisons with an age-matched control group indicated that the four-week HEP resulted in increase in measures of empathy and treatment of animals, although only the increase in empathy levels was significant. This paper discusses the implications of the current results and areas in need of future consideration.
\end{abstract}

\section{Keywords}

Humane Education; CTAQ; empathy

The last decade has seen a proliferation in the study of human-animal interactions generally (e.g. Simmons \& Armstrong, 2007) with a significant number of authors addressing animal cruelty specifically. Much of this depends on the notion that deliberately cruel acts toward animals are indicative of some kind of human "malfunction"-for example, as an indicator of family violence, or antisocial behavior more generally (e.g. Faver \& Strand, 2003). Much of the extant research in this area has been conducted within relatively narrow populations such as incarcerated individuals (e.g. Merz-Perez, Heide \& Silverman, 2001) and women entering domestic violence shelters (e.g. Flynn, 2000). Ascione (2001), in a review of studies with incarcerated individuals, concluded 
that deliberate animal abuse may be typical of the developmental histories of between $25 \%$ and $66 \%$ of violent criminals. Studies also associate animal cruelty with domestic violence and child abuse (e.g., Ascione, 2001; Ascione, Weber \& Wood, 1997) with empirical reports suggesting that animals may be harmed (or killed) to intimidate and control others, especially within domestic violence situations. For example, Ascione et al. surveyed 38 women entering a refuge to escape violence and found that of the $74 \%$ who had companion animals, $71 \%$ had experienced their partner either threatening to harm, or actually harming, their animal.

Another area of significant interest is the effect of witnessing, and/or engaging in, deliberate animal harm by children. In a study by Thompson and Gullone (2006), adolescents who witnessed animal abuse were more likely to engage in animal abuse themselves than members of the same cohort who had not witnessed such abuse. This increase in the propensity to engage in deliberate animal harm is concerning for a number of reasons (beyond the obvious animal welfare issue). For example, Gullone and Robertson (2008) reported that witnessing deliberate animal abuse was a strong predictor for engaging in bullying behaviors as well as animal abuse. Children who abuse animals are often victims of sexual abuse themselves (Adams \& Donovan, 1996) and juveniles who admit to having had sex with nonhuman animals report more sex offenses against humans than other sex offenders of the same sex, age, and race (Fleming, Jory \& Burton, 2002). Researchers also suggest that approximately $25 \%$ of children meeting the criteria for Conduct Disorder (CD) engage in deliberate animal harm and that this behavior is one of the earliest observable symptoms of antisocial behavior and (potentially) childhood psychopathology (Frick et al., 1993; Miller, 2001).

Such research findings have contributed to the burgeoning idea of "The Link" - that is, that those who engage in deliberate harm of animals are more at risk of engaging in various forms of antisocial behavior, including interpersonal violence. Evidence for "The Link," though correlational, seems compelling. For example, Merz-Perez et al. (2001) reported that, when surveying a sample of incarcerated males, those who were convicted of violent humanrelated offences were significantly more likely to have abused animals than those convicted of nonviolent crimes. Similarly, in a study investigating links between childhood cruelty to animals and corporal punishment, Flynn (1999) reported that those who admitted to childhood abuse of animals showed significantly more favorable attitudes toward both the male use of violence within familial settings and corporal punishment. Based upon this, Flynn argued that preventing deliberate animal cruelty in childhood may decrease later tolerance for interpersonal violence, especially against women and children. The utility 
of this conceptual link has been extended more recently, with the inclusion of the role of empathy as a potential mediator of violent behavior directed at both humans and animals. For example, Thompson and Gullone (2003) have suggested that a lack of empathy (both human- and animal-directed) may go some way to accounting for deliberate cruelty to animals. It must be noted, however, that even though low empathy has been linked to poor treatment of animals (e.g., Taylor \& Signal, 2005), and, by extrapolation, humans, factors such as a maladaptive family environment and abusive parental practices are likely to contribute to the development of aggression and violence toward both species (Ascione, 2001; Hastings, Zahn-Waxler, Usher, Robinson \& Bridges, 2000).

Given that human-directed empathy has been both suggested as fundamental to children's psychological and social well-being (Bryant, 1987) and found to be inversely related to propensity for aggression and violence (Hastings et al., 2000), intervention strategies aimed at redressing empathy "deficits" and concomitant antisocial behavior have become an important goal of many researchers. Adopting a definition of empathy as a multidimensional construct incorporating cognitive (understanding) and affective (sharing another's emotional state) components allows for the possibility of designing such intervention strategies (Taylor \& Signal, 2005).

Although not all interventions involve the use of animals or animal-focused information, those that do tend to fall into two general groups, Animal Assisted Therapy (AAT) and Humane Education Programs (HEP). AAT programs are those where an animal is present in, and central to, all sessions conducted (e.g., Parish-Plass, 2008). AAT has been used successfully with numerous populations and is predominantly employed as a therapeutic, as opposed to a teaching, tool. These therapeutic uses may well involve redressing empathy "deficits," as, for example, in the use of AAT with victims of abuse (e.g., Parish-Plass, 2008; Reichert, 1998) but this is included within, and is secondary to, a general therapeutic paradigm aimed at helping the humans involved in the program. Thus, neither redressing empathy "deficits" nor the promotion of proanimal attitudes is the sole focus or aim of such programs. One notable exception within this general category is that of the AniCare Child program which, albeit a therapeutic approach, revolves around teaching empathy as part of the treatment of juveniles who abuse animals.

Alternatively, HEP usually have the development of proanimal attitudes and behaviors as their central aim, with any concomitant benefits to humans as a secondary (although still highly important) factor. Such programs have been suggested as particularly effective mechanisms whereby an overall reduction in violence toward both animals and humans can be achieved. Thus, the 
rationale for HEP is that teaching children kindness to animals will result in animal-directed empathy, which in turn will generalize to human-directed empathy and a concomitant overall reduction in violent/aggressive behavior (Nicoll, Trifone \& Samuels, 2008; Thompson \& Gullone, 2003).

Humane Education dates back to the 1800s, when the Oregon Humane Society (2007) educated people about empathy for animals and empathy for children. Green Chimneys, The Forget Me Not Farm, Youth and Animal Pilot Project, and Chenny Troupe are some of the 2,000 modern programs currently operating within the United States (Kruger, Trachtenberg \& Serpell, 2004). In Australia, the RSPCA provides a variety of community programs that teach empathy, and humane attitudes, toward animals. The Educational Mobile Unit (EMU), for example, is a mobile classroom that visits schools in three states (see http://www.rspcaqld.org.au/emu/ for further details). Despite this modern proliferation of HEP, rigorous empirical research regarding their utility and efficacy remains sparse. Furthermore, the few studies available have often suffered from poor research design, (e.g., inappropriate measures, postHEP testing only, and/or absence of a control group). Adding to the methodological problems already inherent in the evaluation of HEP is the fact that HEP research is based in numerous and diverse disciplines, utilizes disparate frameworks, and can incorporate "animal present" and "literature only" modalities, or a combination thereof, with potentially differing efficacies.

Ascione (1992) points to studies by Malcarne (1981) and Vockell and Hodal (1980), neither of which measured attitudes toward animals prior to any intervention (cited in Ascione, 1992). As a consequence, it is difficult to discern what role, if any, HEP interventions played in participants' final attitudes. Similarly, a control group was lacking in a recent study (Sprinkle, 2008) that reported a reduction in generalized aggression (as measured by outof-school suspensions) and improved empathy in nearly 300 fourth-, fifth-, and sixth-grade children following a HEP. The authors acknowledged that this meant it was impossible to determine whether the significant changes seen were due to the HEP alone, were the result of simple maturation, a combination of both, or some other, extraneous, variable (Sprinkle, 2008). Although results like this are useful, they lack the methodological rigor needed to advance the field.

A few successful HEP evaluations to date, however, have used robust methodology (e.g., pre- and posttesting; valid and reliable measures) and have demonstrated statistically significant results (e.g., Ascione, 1992, 1993; Nicoll, Trifone \& Samuels, 2008). For example, Ascione (1992) implemented and evaluated a 40-hour, year-long, curriculum-based HEP, with first-, second-, fourth-, and fifth-grade children, to assess their attitudes toward the treatment 
of animals. Pre- and posttest questionnaires (i.e., the Primary Attitude Scale [PAS]; the Intermediate Attitude Scale [IAS], and the Bryant Empathy Index [BIE]) assessed children's attitudes toward animals and human-directed empathy and were administered to both a control (no HEP intervention) and an experimental group. Ascione reported that the HEP promoted positive animal-related attitudes within the experimental groups but that this effect was moderated by the age of the children. That is, although he observed qualitative improvements for the first-grade children within animal attitude measures, he noted no difference within the empathy measure. He noted no change in either measure for the second-grade children. In contrast, for the fourthgraders, Ascione noted improvements in both human-directed empathy and attitudes toward animals. For the fifth-graders, he observed changes on the empathy measure alone. Interestingly, Ascione (1993) reported that for the fourth-grade experimental group, the elevated levels displayed on the empathy and attitude toward animals measures were still present 12 months later. Although dated, this finding remains important, as it was one of the first to measure robustly the effects of a HEP, and it remains one of the few to evaluate the long-term effectiveness of HEP. It also serves to highlight another issue involved in the evaluation of HEP - that of age. Given that a number of studies have indicated a differential effect of HEP dependent upon age (e.g., Ascione, 1992; Sprinkle, 2008) it would seem essential either to limit investigations to single age cohorts or to ensure that any analyses acknowledge these age effects (i.e., results should not be concatenated across age groups).

Given the perceived importance of humane education as a proposed mechanism whereby positive treatment of animals, and thus positive treatment of other humans, may be taught, it seems somewhat remiss that relatively few HEP have been rigorously evaluated. Furthermore, recent calls for the inclusion of humane education within broader humanistic, environmental, and social justice frameworks (e.g., McLaren \& Houston, 2004; Thomas \& Beirne, 2002) also underline the importance of HEP beyond a simple "treatment of animals" model. It is therefore timely to instigate and rigorously analyze more HEP in terms of their general utility and their efficacy regarding specific attitudinal and behavioral changes. The current study falls within the latter category, as it aimed to evaluate the efficacy of a specifically designed HEP in terms of changes it might lead to in both treatment of animals and humandirected-empathy. 


\section{Method}

\section{Participants}

Thirty-seven fourth-grade students (all approximately nine years old) from two separate classes within a representative state-run school in Queensland, Australia, served as participants. The experimental (E) group underwent an HEP, whereas the control (C) group did not. The E group consisted of 11 boys and 12 girls; the $\mathrm{C}$ group consisted of 5 boys and 9 girls.

\section{Apparatus}

The first section of the questionnaire contained a small number of basic demographic questions such as age, gender, presence of a companion animal at home, etc. The second section comprised two psychometric measures as detailed below:

The Children's Treatment of Animals Questionnaire, CTAQ (Thompson \& Gullone, 2003), is a recently developed, 13-item, self-report measure of children's humane behavior toward nonhuman animals. Respondents indicate whether they engage in a particular activity with their companion animal (or imaginary companion animal if the child does not have one). For example, participants are asked if they "Play with," "Yell at," or "Cuddle" their companion animal, with the response format being: "Often" (score = 3), "Sometimes" (score $=2$ ), or "Never" (score $=1$ ). Higher scores (following reverse coding where necessary) reflect more humane treatment toward animals. The psychometric properties of CTAQ are considered acceptable, with good internal consistency (i.e., Cronbach's alpha yielded coefficients of 0.81 ) and good test-retest reliability (i.e., a coefficient of 0.64 ).

Bryant's Empathy Index, BIE (Bryant, 1982), is a 22-item, self-report measure designed to assess human-directed empathic tendencies in children, which has been used previously in other companion animal studies with children (e.g., Ascione, 1992). A YES/NO (1 or 0 for yes/no) response format was selected as more appropriate for the current participants, with higher scores reflecting greater empathy. Sample items include: "I get upset when I see a boy being hurt"; "It's silly to treat dogs and cats as though they have feelings like people." Internal consistency is acceptable, with Cronbach alphas reported from 0.54 to 0.79 and good test-retest reliability (0.83). Both convergent and discriminant validity have been demonstrated (Bryant, 1982). 


\section{Procedure}

The primary researcher approached two schools and discussed the possibility of implementing an HEP. The school most able to do so within a suitable time frame was selected. Two teachers from this school volunteered to take part in the research. The HEP intervention was provided by an independent RSPCA Education Officer. The principal researcher (a qualified teacher) and the RSPCA education officer codesigned the HEP lessons. (A brief outline of these is available at the end of the paper; full lesson plans are available upon request from the corresponding author.) These lessons were reviewed by both the school principal and the E group teacher prior to implementation. Each lesson was designed to take one hour, with the E group receiving two onehour lessons per week for four consecutive weeks. The lessons were designed to deal with both issues of general animal husbandry and care (e.g., approaching dogs safely and nutritional needs) and animal cruelty issues specifically (e.g., Five Freedoms and definitions of animal cruelty). Participants were not made aware of the specific aims of the project, instead being told on a general level that the study would investigate attitudes to both animals and people in different situations. Although this eight-hour intervention is relatively short, it is similar to that of previously successful HEP and was designed specifically to fit within established school curricula.

The researcher sought both parental and student consent to participate, and only those children who had both took part in the current research. Those for whom consent was not granted participated in an alternative activity organized by the school. Although recruitment for the E group was not difficult, participation in the $\mathrm{C}$ group was not as high, resulting in disparate participant numbers. Once all consent forms were collected, a pretest questionnaire was administered to both the $\mathrm{E}$ and $\mathrm{C}$ groups by the principal researcher. This questionnaire contained demographic questions - the CTAQ and the BIE. If students were absent on testing day, the test was completed as soon as they returned to school. The researcher defined words on the tests that students indicated that they did not understand. Following the pretest, the HEP intervention was delivered as outlined above. At the completion of the four-week intervention period, the principal researcher returned to the school and administered the posttest questionnaire to both the $\mathrm{E}$ and $\mathrm{C}$ groups, as for the pretest questionnaire.

Results

Data from the pre- and postcollection times were entered into SPSS (v13), checked for errors, and negatively worded items were reverse coded prior to 
any analyses. Cronbach alphas for the CTAQ (pre $=0.862$, post $=0.863$ ) and BIE (pre $=0.773$, post $=0.789$ ) were calculated and found to be high. An independent samples $t$ test was employed to determine if the scores on the CTAQ and BIE were significantly different across the $\mathrm{E}$ and $\mathrm{C}$ groups at the first measure (i.e., preintervention). Despite apparently higher scores on the CTAQ for the control group, there was no systematic difference between the two groups $(t(35)=0.964, p=0.342)$; similarly, although BIE scores were higher for the E group preintervention, this difference was likely due to chance $(t(35)=-0.718, p=0.477)$. Presented in Table One are the average scores (and deviations) for pre- and postintervention collection points separated by group (i.e., $\mathrm{E}$ and $\mathrm{C}$ ).

Table 1. Pre- and post- CTAQ and BIE scores across Experimental and Control groups

\begin{tabular}{lcccc}
\hline & \multicolumn{2}{c}{ Preintervention } & \multicolumn{2}{c}{ Postintervention } \\
Group & CTAQ & BIE & CTAQ & BIE \\
\hline Experimental & $28.13(4.95)$ & $13.49(4.39)$ & $28.61(5.73)$ & $14.78(4.00)$ \\
Control & $29.64(4.03)$ & $12.50(3.30)$ & $29.64(4.16)$ & $12.21(4.49)$ \\
\hline
\end{tabular}

As can be seen in the table, an increase in both CTAQ and BIE scores was observed postintervention for the E group, whereas no significant change was seen within the control group. Although the increase seen across BIE scores (within the E group) was significant $(t(22)=-2.389, p=0.026)$, the increase in CTAQ scores proved nonsignificant $(t(22)=-0.503, p=0.620)$. Similarly, the decrease seen in BIE scores for the control group proved nonsignificant $(t(22)=0.310, p=0.762)$. Interestingly, when the change in BIE score was analyzed for boys and girls separately, the significant difference observed only held true for the boys in the sample $\left(\mathrm{BIE}_{\text {boys }} t(10)=-2.456, p=0.034 ; \mathrm{BIE}_{\text {girls }} t(11)=-\right.$ $0.788, p=0.447$ ). Similarly (although not significant), the largest change in CTAQ scores was seen for boys. Presented in Table Two are the means and standard deviations for pre- and post-CTAQ and BIE scores separated by gender for the E group only.

\section{Discussion}

The purpose of the current study was to evaluate a pilot HEP intervention with fourth-grade students. The results showed that, although both empathy 
Table 2. Average pre- and post- CTAQ and BIE scores separated by gender-Experimental group only

\begin{tabular}{lcccc}
\hline & \multicolumn{2}{c}{ Preintervention } & \multicolumn{2}{c}{ Postintervention } \\
Group & CTAQ & BIE & CTAQ & BIE \\
\hline Male & $27.27(5.16)$ & $10.64(3.56)$ & $28.36(5.50)$ & $12.91(3.70)$ \\
Female & $28.92(4.83)$ & $16.08(3.40)$ & $28.83(6.16)$ & $16.50(3.58)$ \\
\hline
\end{tabular}

(BIE) and treatment of animals scores (CTAQ) increased following the intervention, only the empathy increase in boys was actually significant. Although not significant, the largest change in CTAQ scores was also noted for boys. Thus, this particular HEP intervention appears to have had more impact on male, rather than female, children. This is a particularly interesting finding, given the consistent gender effect seen within the Human-Animal Interaction studies field more generally (i.e., females generally score higher on measures of proanimal attitudes; for an overview of this see Herzog, 2007). This result would suggest that boys may be a particularly valuable cohort to target with HEP, especially given that males are overrepresented in the commission of violent interpersonal crimes and deliberate animal cruelty (Ascione, 2001). Evaluation of gender-related outcomes is sparse within the HEP literature. For example, although Nicoll et al. (2008) report correlations between gender and scores on the Pet Attitude Scale (with girls scoring higher than boys) only combined pre- and postscores are presented, masking any potential gender effects. Exactly why boys showed a greater change following the HEP in the current study is unclear. It may, however, be a reflection of the fact that boys (and males generally) tend to have lower empathy levels and therefore have "more room to move." That is, as suggested by Thompson and Gullone (2003), where empathy is already at "normative/high" levels (as for girls in the current study), change following an intervention is not likely (i.e., similar to a ceiling effect).

Nicoll et al. (2008) note that, although they reported an increase in proanimal attitudes, there was not a concomitant increase in proanimal behavior (as measured by self-reported interactions with companion animals). This is an important issue for HEP research, as there is arguably a large gap between attitudes and actual behavior. The current study attempted to measure actual behaviors using the CTAQ, and, although there was not a significant change, there was a general improvement in self-rated treatment of animals for boys. The lack of a significant change in actual behavior may reflect a ceiling effect; that is, in "normally" developing children, appropriate behaviors toward ani- 
mals may be high and thus no statistically significant change would be seen following an HEP. Arguably, however, any positive change in behaviors toward animals can be considered a success. Future investigations of HEP would benefit from using a measure like the CTAQ to benchmark normative levels of behavior toward animals in children. This would then enable comparison with children who engage in cruel acts toward animals and an assessment of the efficacy of HEP within this population.

Another issue in need of consideration is the potential benefits and problems of including live animals within HEP. Although AAT (where an animal is always present) has been more widely researched (and more of a consensus regarding its efficacy reached, e.g., Nimer \& Lundahl, 2007; Souter \& Miller, 2007), some researchers are beginning to question the impact that AAT may have on the animals involved, arguing that the human-derived benefits may not outweigh the negative impact on the animals (e.g., Hatch, 2007; Serpell, Coppinger \& Fine, 2000). Given that the aim of HEP is to promote animal welfare-friendly behavior and attitudes (often in children), any potential negative effects for the animals involved is of paramount importance and something that is in need of urgent research attention. It may be the case that literature-based HEP are more appropriate than ones where a live animal is brought into the classroom. However, little assessment of the relative efficacy of animal-present vs. animal-absent HEP has occurred. In a recent study where this was examined, Nicoll et al. (2008) reported no significant effect of the literature-only intervention; its implementation, however, was not optimal, limiting the utility of the comparison (i.e., literature was given to the participants, but no formal "teaching" of the material occurred). Although the current pilot study utilized an intensive, four-week, literature-based approach and did find significant changes in empathy levels, it may be that an HEP with an animal present would have proved more effective (i.e., resulted in significant improvements in CTAQ scores as well).

On a philosophical note, although HEP do seem to demonstrate some efficacy in increasing human- (and animal-) directed empathy levels, it must be noted that one particular problem with this approach is the underlying assumption that animals_-or at least knowledge regarding animals—are tools. One assumption underlying HEP is that humans will benefit in some way. Although animal welfare is cited as a concern by most proponents of humane education, it is often seen as tangential to human benefits (particularly when being considered for inclusion within school curricula). This is particularly the case when HEP (with animals present) are used primarily to redress human empathy deficits, thereby preventing later human-directed problems. Whereas the limited literature in this area seems to support the utility of HEP in such 
a way, it may be that positing (knowledge about) animals as a tool to help humans actually undermines the very idea that HEP are aiming to challenge in the first place: the poor treatment of animals (Taylor \& Signal, 2008).

In conclusion, HEP may be an effective way to increase both appropriate attitudes to (and behaviors toward) animals and human-directed empathy. There is an urgent need, however, for more, empirically sound, research regarding both overall effectiveness and the variables that may impact efficacy. For example, although the current pilot study goes some way to suggest that brief, literature-only interventions can have a measurable effect on empathy levels and attitudes toward animals, it is beyond the scope of the study to investigate the long-term effects of such interventions. It would also be interesting to examine the wider effect of such interventions-i.e., is there any generalization to the family of the children undergoing the intervention? Would "takehome" exercises promote such generalization and potentially long-term changes in attitudes and behavior?

\section{References}

Adams, C., \& Donovan, J. (Eds.). (1996). Animals and women: Feminist theoretical explanations. Durham, NC: Duke University Press.

Ascione, F. (1992). Enhancing children's attitudes about the humane treatment of animals: Generalization to human-directed empathy. Anthrozoös, 5 (3), 176-191.

- (1993). Children who are cruel to animals: A review of research and implications for developmental psychopathology. Anthrozoös, 6 (4), 226-247.

(2001, September). Animal abuse and youth violence. OJJDP: Juvenile Justice Bulletin, 1-15.

Ascione, F., Weber, C., \& Wood, D. (1997). The abuse of animals and domestic violence: A national survey of shelters for women who are battered. Society \& Animals, 5 (3), 205-218.

Bryant, B. (1982). An index of empathy for children and adolescents. Child Development, 53, 413-425.

- (1987). Mental health, temperament, family, and friends: Perspectives on children's empathy and social perspective taking. In N. Eisenberg \& J. Strayer (Eds.), Empathy and its Development (pp. 245-270). Cambridge: Cambridge University Press.

Faver, C. A., \& Strand, E. B. (2003). Domestic violence and animal cruelty: Untangling the web of abuse. Journal of Social Work Education, 39 (2), 237-253.

Fleming, W., Jory, B., \& Burton, D. (2002). Characteristics of juvenile offenders admitting sexual activity with non-human animals. Society \& Animals, 10 (1), 31-45.

Flynn, C. P. (1999). Exploring the link between corporal punishment and children's cruelty to animals. Journal of Marriage and the Family, 61 (4), 971-981.

(2000). Why family professionals can no longer ignore violence toward animals. Family Relations, 49 (1), 87-95.

Frick, P. J., Lahey, B. B., Loeber, R., Tannenbaum, L. E., Van Horn, Y., Christ, M. A. G., Hart, E. A., \& Hansen, K. (1993). Oppositional defiant disorder and conduct disorder: A metaanalytic review of factor analyses and cross-validation in a clinic sample. Clinical Psychology Review, 13, 319-340. 
Gullone, E., \& Robertson, N. (2008). The relationship between bullying and animal abuse behaviors in adolescents: The importance of witnessing animal abuse. Journal of Applied Developmental Psychology, 29 (5), 371-379.

Hastings, P. D., Zahn-Waxler, C., Robinson, J., Usher, B., \& Bridges, D. (2000). The development of concern for others in children with behavior problems. Developmental Psychology, $36(5), 531-546$.

Hatch, A. (2007). The view from all fours: A look at an animal-assisted activity program from the animals' perspective. Anthrozoös, 20 (1), 37-50.

Herzog, H. A. (2007). Gender differences in human-animal interactions: A review. Anthrozoös, 20(1), 7-22.

Kruger, K. A., Trachtenberg, S. W., \& Serpell, J. A., (2004). Can Animals Help Humans Heal? Animal-Assisted Interventions in Adolescent Mental Health. Philadelphia, PA: Center for the Interaction of Animals and Society, University of Pennsylvania, School of Veterinary Medicine.

McLaren, P., \& Houston, D. (2004). Revolutionary ecologies: Ecosocialism and critical pedagogy. Educational Studies, 36 (1), 27-44.

Merz-Perez, L., Heide, K. M., \& Silverman, I. J. (2001). Childhood cruelty to animals and subsequent violence against humans. International Journal of Offender Therapy and Comparative Criminology, 45 (5), 556-573.

Miller, C. (2001). Childhood animal cruelty and interpersonal violence. Clinical Psychology Review, 21 (5), 735-749.

Nicoll, K., Trifone, C., \& Samuels, W. E. (2008). An in-class, Humane education programme can improve young students' attitudes toward animals. Society \& Animals, 16, 45-60.

Nimer, J., \& Lundahl, B. (2007). Animal-assisted therapy: A meta-analysis. Anthrozoös, 20 (3), 225-238.

Oregon Humane Society (2007). History: Past, present and future. Retrieved March 15, 2007, from http://www.oregonhumane.org/history.htm.

Parish-Plass, N. (2008). Animal-assisted therapy with children suffering from insecure attachment due to abuse and neglect: A method to lower the risk of intergenerational transmission of abuse? Clinical Child Psychology \& Psychiatry, 13 (1), 7-30.

Reichert, E. (1998). Play and animal assisted therapy: A group treatment model for sexually abused girls ages 9-13. Family Therapy, 21 (1), 55-62.

Serpell, J. A., Coppinger, R., \& Fine, A. (2000). The welfare of assistance and therapy animals: An ethical comment. In A. Fine (Ed.) Handbook on animal-assisted therapy: Theoretical foundations and guidelines for practice. New York: Academic Press, pp. 415-431.

Simmons, L., \& Armstrong, P. (Eds.). (2007). Knowing Animals. Boston: Brill.

Souter, M. A., \& Miller, M. D. (2007). Do animal-assisted activities effectively treat depression? A meta-analysis. Anthrozoös, 20 (2), 167-180.

Sprinkle, J. E. (2008). Animals, empathy, and violence: Can animals be used to convey principles of prosocial behavior to children? Youth Violence and Juvenile Justice, 6 (1), 47-58.

Taylor, N., \& Signal, T. (2005). Empathy \& attitudes towards animals, Anthrozoös, 18 (1), 18-27.

- (2008). Throwing the baby out with the bathwater: Towards a sociology of the humananimal abuse 'link.' Sociological Research Online, 13 (1/2).

Thomas, S. C., \& Beirne, P. (2002). Humane education and humanistic philosophy: Toward a new curriculum. Journal of Humanistic Counseling, Education and Development, 41 (2), 190-199.

Thompson, K. L., \& Gullone, E. (2003). The children's treatment of animals questionnaire (CTAQ): A psychometric investigation. Society \& Animals, 11 (1), 1-15.

- (2006). An investigation into the association between the witnessing of animal abuse and adolescents' behavior toward animals. Society \& Animals, 14, 223-243. 


\section{Appendix}

\section{HEP LESSON OBJECTIVES}

\begin{tabular}{ll}
\hline Lesson One: & Students are introduced to the work of the RSPCA, the \\
& RSPCA education officer, and "Bob" (a large toy dog) \\
& via class discussion and video. Each child makes a pet \\
& whom they are responsible for over the four-week program \\
& (including weekends). \\
\hline Lesson Two: & $\begin{array}{l}\text { Students respond to visual stimuli of dogs expressing } \\
\text { different emotions (e.g., happy, scared). They will practice } \\
\text { different steps regarding how to approach and handle dogs } \\
\text { safely and how to identify different emotions/actions of } \\
\text { animals. }\end{array}$ \\
\hline Lesson Three: & $\begin{array}{l}\text { Through discussion and hands-on activities (with pet } \\
\text { created in Lesson One and Bob's story), students will } \\
\text { develop an understanding of how to be a responsible pet } \\
\text { guardian. Through dramatization, children will explore the } \\
\text { idea that animals have feelings. }\end{array}$ \\
\hline Lesson Eight: & $\begin{array}{l}\text { Through whole-class and small-group discussion, students } \\
\text { will investigate responsible pet guardianship and animal } \\
\text { cruelty. Students will develop an understanding of why } \\
\text { and how we should care for, and have compassion toward, } \\
\text { animals and people. Students will voice their opinions } \\
\text { regarding various animal welfare issues and give reasoning } \\
\text { for these opinions. Five Freedoms covered. }\end{array}$ \\
\hline Lesson Seven: & $\begin{array}{l}\text { The students will be able to experience firsthand the work } \\
\text { of the RSPCA. Students will visit the RSPCA, exploring } \\
\text { the different areas of wildlife, vets, inspectors, training, } \\
\text { and volunteers, as well as the everyday running of the } \\
\text { organization and caring for the animals at the RSPCA. } \\
\text { qualities of friendship and why friends are important. } \\
\text { Students will explore how animals can be friends and how } \\
\text { they communicate with people. }\end{array}$ \\
\hline $\begin{array}{l}\text { Through whole-class discussion, the students will develop } \\
\text { a class charter that will be a guideline for the students } \\
\text { to help their animals be healthy and happy at all times. } \\
\text { Students will create a kindness web for another class } \\
\text { member to help them realize that all humans are special in }\end{array}$ \\
\hline
\end{tabular}

